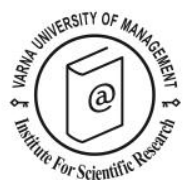

\title{
Vodenska, M. (Ed.) (2018) Hospitality and Tourism in Transition in Central and Eastern Europe: A Comparative Analysis. Cambridge Scholars Publishing. 502 pp., ISBN 978-1-5275-1120-0
}

\author{
Reviewed by Petr Scholz ${ }^{1 *}$
}

Received: 28/09/2018

${ }^{1}$ College of Polytechnics Jihlava, Tolstého 16, 586 01, Czechia, e-mail: petr.scholz@vspj.cz

* Corresponding author

(c) 2019 Varna University of Management. All rights reserved

Citation Vodenska, M. (Ed.) (2018) Hospitality and Tourism in Transition in Central and Eastern Europe: A Comparative Analysis. Cambridge Scholars Publishing. 502 pp., ISBN 978-1-5275-11200. Reviewed by Petr Scholz, European Journal of Tourism Research 21, pp. 155-157

The book brings an exciting and comprehensive view of tourism in selected countries. The analysis was performed by thirty-five researchers from eleven countries in Central and Eastern Europe: Albania, Bulgaria, Croatia, Czechia, Hungary, Latvia, Macedonia, Montenegro, Romania, Serbia, and Slovenia. The analysis aimed at revealing hospitality and tourism development in the studied countries during the $1990-2015$ period.

The structure for each country consists of nine subchapters. The first subchapter ('Introduction') deals with general information about the country (e.g. location, total area, population, and currency), political structure and administrative-territorial structure and their changes.

The second subchapter ('Hospitality and Tourism Development and Importance') is about the historical development of tourism and hospitality until the beginning of transition (e.g., restrictions on outgoing tourism, mainly to "western countries", widespread of domestic tourism, number of participants in outgoing and incoming tourism). This subchapter also highlights the economic importance of tourism, its contribution to employment and GDP of a country.

The third subchapter ('Hospitality and Tourism Demand') focuses on the main tourism markets, international and domestic tourism before and after the transition. In particular, it provides information about the number of international arrivals from abroad (transit visitors and visitors with a tourist purpose) and domestic arrivals, too. The data are supported by appropriate figures and charts. In the majority of surveyed countries, daily expenditure in euro, average stay, and the number of international overnights are reported as well.

The fourth subchapter ('Hospitality and Tourism Supply') introduces the changes a country's tourism industry experienced during the transition period. For each country the main services are listed, e.g., transport, accommodation, and catering services. It provides information about air, railway, road, water, and public transportation, e.g., cable cars and lifts and which type of transportation is 
Vodenska, M. (Ed.) (2018) Hospitality and Tourism in Transition in Central and Eastern Europe: A Comparative Analysis. Cambridge Scholars Publishing. 502 pp., ISBN 978-1-5275-1120-0. Reviewed by Petr Scholz, European Journal of Tourism Research 21, pp. 155-157

the most developed in the country. In the analyzed countries, development and subsequent growth of accommodation facilities played a significant role. Notably, the accommodation facilities went through fundamental changes in the transition period to a market economy. Before 1989 they were owned by the state, eventually public organizations. After this year there was a massive growth of accommodation facilities. Especially, the number of rooms and beds in First Class and Luxury hotels increased, stimulated by the entry of international hotel chains like Hilton, Marriott, or Holiday Inn into the respective country markets. Various charts visualize the changes in the capacity and category structure of collective accommodation facilities, and the number of guests in them. This subchapter also elaborates on tourist information centers and travel agencies, and package tours as well.

The fifth subchapter ('Tourism Types and Destinations') offers an insight into the various types of tourism in a country, e.g., mountain tourism, rural tourism, ecotourism, urban and cultural tourism, spa tourism, religious tourism, recreation by the sea, congress and exhibition tourism, health tourism, wine tourism, and shopping tourism. All of the surveyed countries have good potential and conditions for tourism development. The most attractive and visited regions or tourism destinations are mentioned for each country.

The sixth subchapter ('Hospitality and Tourism Human Capital') shows that human capital is irreplaceable for tourism development regardless of the adoption of information and communication technologies. The chapters' authors provide data for the number of employees and average gross monthly wage in tourism and hospitality. In some chapters that authors also elaborate the structure of employees in tourism (accommodation and catering services) and their qualification.

The seventh subchapter ('Tourism Policy, Planning and Management') focuses on the management of tourism in the selected countries which has undergone considerable changes over the years. Most countries have a 156 special tourism authority at national level which is subordinate to the Ministry responsible for tourism development, marketing and management. Their mission is the planning, implementation and monitoring of different activities under the tourism policy and tourism development strategy of the country.

The eighth subchapter is called 'Tourism Impacts and their Manifestation in the Transition Period'. Contemporary tourism development at local, regional and national levels should be planned following the principles of sustainability, considering its environmental, social, cultural, and economic aspects. The success of individual economies and their position on the world market is markedly manifested in the living standard of the population. This subchapter informs about the economic impact of tourism, employment rate, net income generated by the tourism in a country, and how much money was invested in its tourism industry. Positive and negative socio-cultural impacts are observed in each destination. The positive ones outlined by the authors include increased support for traditional cultures and ethnic contexts, revitalization of the conventional art, festivals and languages, growing social opportunities, new economic and social opportunities suppressing social inequality, etc. The negative impacts are primarily overpopulation, traffic collapse, crime, loss of residents' access to places and facilities for spent leisure time and rest, demonstration effect, and changes in traditional activities and crafts to meet consumer demand for visitors.

The ninth subchapter ('Hospitality and Tourism Education') describes the situation about tourism education before and after the transition period. Until 1989, not so many high schools and universities were interested in and taught tourism besides the state schools for chefs, cooks, and waiters. After 1989, there was a considerable development of schools teaching tourism and preparing experts for this sector at various levels of study and with different quality. The authors state that it is necessary to focus on an apprenticeship in the field, completion of secondary studies, completion of higher professional education, 
completing higher studies at Bachelor's and Master's level.

I would recommend this book for use as a supporting text for academic staff, university and college students, researchers in the hospitality and tourism sector, and everybody who is interested in the tourism development of Central and Eastern European countries. The book brings a good review and practical information about hospitality and tourism in these countries and provides a strong basis for further exploration and the eventual use of data in the tourism development strategies at the destination management level. The book is useful and helpful in the teaching and pedagogical process. Some data may be used for more in-depth comparative analysis.
On the other hand, the book would benefit of more sophisticated statistical analysis, e.g. correspondence, factor or cluster analysis. A few subchapters could be more elaborate and more academic references could be used for define some of the terms. Unfortunately, several figures are not of sufficient quality, and the scale is missing on some maps.

Overall, the book contains good information that can be the basis for more detailed tourism research projects in the selected countries. The significant advantage of the book is its comprehensiveness - all of the information about tourism development during the transition period in Central and Eastern Europe is found in one book only. 